\title{
Human Very Low Density Lipoproteins and Chylomicrons Can Protect against Endotoxin-induced Death in Mice
}

\author{
H. W. Harris, C. Grunfeld, K. R. Feingold, and J. H. Rapp \\ Departments of Surgery and Medicine, San Francisco Veterans Administration Medical Center, San Francisco, California 94121
}

\begin{abstract}
Endotoxemia stimulates many physiologic responses including disturbances in lipid metabolism. We hypothesized that this lipemia may be part of a defensive mechanism by which the body combats the toxic effects of circulating endotoxin. We tested the effects of mixtures of endotoxin, lipoproteins, and lipoprotein-free plasma and determined the ability of varying concentrations of human very low density lipoproteins (VLDL) and chylomicrons, as well as low density lipoproteins (LDL) and high density lipoproteins (HDL), and of the synthetic lipid emulsion SOYACAL to prevent endotoxin-induced death in mice. This study demonstrates that the triglyceride-rich VLDL and chylomicrons, as well as cholesterol-rich LDL and HDL, and cholesterol-free SOYACAL can protect against endotoxin-induced death. Protection required small amounts of lipoprotein-free plasma, and depended on the incubation time and the concentration of lipoprotein lipid. Despite stringent techniques to prevent exogenous endotoxin contamination eight of ten duplicate VLDL preparations contained endotoxin $(5,755 \pm 3,514 \mathrm{ng}$ endotoxin/mg triglyceride, mean \pm SEM) making the isolation of endotoxin-free VLDL difficult. In contrast, simultaneous preparations of LDL and HDL were relatively free of endotoxin contamination ( $3 \pm 3$ and $320 \pm 319$ $\mathrm{ng} / \mathrm{mg}$ total cholesterol, respectively), suggesting that the contamination of VLDL occurs in vivo and not during the isolation procedure. These observations suggest a possible role for increased triglyceride-rich lipoproteins in the host's defense against endotoxemia and infection. (J. Clin. Invest. 1990. 86:696-702.) Key words: detoxification • endotoxemia $\bullet$ lipoproteins $\bullet$ triglycerides
\end{abstract}

\section{Introduction}

Endotoxemia can stimulate a variety of physiologic responses including fever (1), leukocytosis (1), hypotension (2), induction of acute-phase reaction proteins (3), and disturbances in glucose and lipid metabolism (4-7). One of the earliest metabolic responses is an increase in plasma very low density lipoprotein (VLDL) levels $(8-10)$, which has been proposed to represent the mobilization of peripheral energy stores to fuel the body's response to the infectious challenge $(11,12)$. However, lipoproteins may function in roles other than the transport of lipid during periods of physiological stress. Some authors have suggested that lipoproteins are directly involved in

Address reprint requests to Dr. Rapp, VAMC No. 112, 4150 Clement Street, San Francisco, CA 94121.

Received for publication 9 February 1990 and in revised form 24 April 1990

The Journal of Clinical Investigation, Inc.

Volume 86, September 1990, 696-702 the host response to infection and tissue destruction (7). It is possible that the endotoxin-induced hyperlipoproteinemia may represent a physiological defense mechanism wherein the body attempts to combat the toxic effects of circulating endotoxin.

Endotoxin has been shown to interact with cholesterol ester-rich lipoproteins. Ulevitch et al. (13-16) have elegantly demonstrated the ability of high density lipoproteins (HDL) to bind endotoxin as part of a two-step process requiring serum. Initially serum appears to disaggregate macromolecules of endotoxin. Subsequently, the disaggregated endotoxin binds to HDL as evidenced by a decrease in endotoxin's buoyant density when ultracentrifuged in a $\mathrm{CsCl}$ gradient. Once endotoxin is bound to HDL its ability to induce fever, leukocytosis, and hypotension are dramatically reduced $(13,14)$. The binding of endotoxin to HDL also prevents endotoxin-induced death in sensitized (adrenalectomized) mice but not in rabbits $(13,17)$. Whereas Ulevitch and co-workers primarily focused on the interaction between HDL and endotoxin, Van Lenten et al. (18), using New Zealand White rabbits, demonstrated that LDL can also bind endotoxin in much the same way. Endotoxin bound to LDL showed less toxicity to endothelial cells, although it was capable of initiating some components of the inflammatory response (19).

If endotoxin-induced lipemia, which usually begins with an increase in VLDL, is part of a host defensive response, then the binding of endotoxin by triglyceride $(\mathrm{TG})^{1}$-rich lipoproteins may be of central importance. Previous studies that have examined this issue showed that the TG-rich VLDL had much less ability to interact and form complexes with endotoxin than did the cholesterol-rich lipoproteins LDL and HDL (14, 18). One study suggested that the reason for this difference may be that a lipoprotein's ability to interact with endotoxin is directly proportional to its cholesterol content (18). This study demonstrated that endotoxin binding was substantially increased in the $\beta$-VLDL-enriched VLDL fraction from Watanabe heritable hyperlipidemic and cholesterol-fed rabbits over controls (18). The interaction of chylomicrons with endotoxin has not been examined.

The purpose of this study was to determine whether human VLDL and chylomicrons can protect mice against endotoxin-induced death, and to determine whether a lipid particle containing no cholesterol can also be protective. To address this question we measured survival in mice injected with a mixture containing a lethal dose of endotoxin, lipoproteinfree plasma, and either triglyceride-rich lipoproteins or SOYACAL, an emulsion of large particles containing neutral triglycerides and no cholesterol. Special precautions were taken to avoid introducing exogenous endotoxin into the lipo-

1. Abbreviations used in this paper: TC, total cholesterol; TG, triglyceride. 
protein preparations. We also looked for evidence that VLDL can have a role in defending humans against endotoxemia by determining whether human VLDL is frequently contaminated with endogenously acquired endotoxin.

\section{Methods}

Reagents and solutions. American Chemical Society (ACS) chloroform; reagent grade ortho-phosphoric acid, $\mathrm{KBr}$, glacial acetic acid (Fisher Scientific Co., Fairlawn, NJ) and $\mathrm{NaOH}$ (J. T. Baker Chemical Co., Phillipsburg, NJ); apyrogenic, preservative-free $0.9 \% \mathrm{NaCl}$ (Kendall McGraw Labs, Inc., Irvine, $\mathrm{CA}$ ) and $\mathrm{H}_{2} \mathrm{O}$ (Elkins-Sinn, Inc., Cherry Hill, NJ); $3 \% \mathrm{H}_{2} \mathrm{O}_{2}$ (Cumberland Co., Smyrna, TN); D-galactosamine hydrochloride (Sigma Chemical Co., St. Louis, MO); SOYACAL $20 \%$ intravenous lipid emulsion containing $20 \%$ soybean oil (triglycerides), $1.2 \%$ egg yolk phospholipid, and $2.21 \%$ glycerin, (Alpha Therapeutic Corp., Los Angeles, CA) were used as specified. The $\mathrm{KBr}$ and PBS used in all experiments were tested and found free of detectable endotoxin.

Escherichia coli, strain 055:B5 endotoxin (Difco Laboratories, Detroit, MI) was reconstituted with sterile, apyrogenic $\mathrm{H}_{2} \mathrm{O}$ to a concentration of $1 \mu \mathrm{g} / \mathrm{ml}$, and stored in 3-ml aliquots at $-70^{\circ} \mathrm{C}$. This preparation of endotoxin was isolated via the phenol extraction technique of Westphal et al. (20) and had a specific activity of 15 endotoxin units (EU)/ng (U. S. Pharmicopeia reference endotoxin).

Depyrogenation. To avoid contamination with exogenously derived endotoxin, all heat-stable materials used in the isolation, processing, and assay of solutions to be injected into the mice, including test tubes, stoppers, beakers, pipettes, ultracentrifuge tubes, and O-rings, were rendered sterile and free of detectable endotoxin $(\leq 5-10 \mathrm{pg} / \mathrm{ml})$ by a combination of steam autoclaving followed by dry heating at $180^{\circ} \mathrm{C}$ for a minimum of $4 \mathrm{~h}(21,22)$. All lipoproteins were isolated using depyrogenated stainless steel ultracentrifuge tubes (Beckman Instruments, Palo Alto, CA) with custom-crafted silicone O-rings. To remove any adherent endotoxin, the dialysis tubing (Spectrapor 3, Spectrum Medical Industries, Inc., Los Angeles, $\mathrm{CA}$ ) was autoclaved in $3 \% \mathrm{H}_{2} \mathrm{O}_{2}$ and then stored in apyrogenic saline at $4^{\circ} \mathrm{C}(23)$.

Plasma. Human venous blood was collected from alcohol-cleansed antecubital fossae of 16 healthy volunteers into sterile plastic syringes containing endotoxin-free heparin (Sigma Chemical Co.), producing a final concentration of $10 \mathrm{IU} / \mathrm{ml}$ and immediately placed on ice. Plasma was expeditiously separated by centrifugation at $2,000 \mathrm{~g}$ for 20 min at $25^{\circ} \mathrm{C}$, and was then stored in depyrogenated glass tubes at $4^{\circ} \mathrm{C}$ until further processing or analysis. Plasma samples were processed within $\mathbf{4 8} \mathrm{h}$ of their collection.

Lipoproteins were isolated from the plasma of healthy, normolipidemic volunteers after at least a 12-h fast using the method of Havel et al. (24) with a few modifications. Briefly, VLDL was isolated by ultracentrifugation at plasma density $\left(d=1.006 \mathrm{~g} / \mathrm{cm}^{3}\right)$, at $100,000 \mathrm{~g}$ for 18 $\mathrm{h}$, at $12^{\circ} \mathrm{C}$ in a ultracentrifuge (L5-50, Beckman Instruments, Inc., Fullerton, CA) using a 40.3 or a Sorval $50.38 \mathrm{Ti}$ rotor (Beckman Instruments, Inc., and DuPont Co., Wilmington, DE, respectively). LDL was isolated as the $d=1.006-1.063 \mathrm{~g} / \mathrm{cm}^{3}$ fraction after adjustment of the density with solid, endotoxin-free $\mathrm{KBr}$. HDL was isolated as the $d=1.063-1.21 \mathrm{~g} / \mathrm{cm}^{3}$ fraction. Chylomicrons were isolated from postprandial plasma by ultracentrifugation at plasma density, at $28,000 \mathrm{~g}$ for $30 \mathrm{~min}$, at $12^{\circ} \mathrm{C}$. The chylomicron fraction was washed by floatation through $1-2$ vol of $50 \mathrm{mM}$ PBS ( $\mathrm{pH}=7.4$ ) in a 40.3 rotor at $28,000 \mathrm{~g}$ for $30 \mathrm{~min}$, at $12^{\circ} \mathrm{C}$. Lipoproteins were exhaustively dialyzed against $0.9 \% \mathrm{NaCl}$ where appropriate. Lipoprotein fractions were used within $7 \mathrm{~d}$ of their isolation. Endotoxin-free PBS was used when diluting lipoproteins.

Lipoprotein-free plasma was isolated from a $d=1.21 \mathrm{~g} / \mathrm{cm}^{3}$ spin of pooled normal human plasma, reconstituted with endotoxin-free PBS to its original volume.

The TG and cholesterol content of lipoproteins was determined using standard enzymatic assays (Sigma Chemical Co. and Wako Chemicals USA, Inc., Dallas, TX).
Assays for endotoxin. All solutions that did not contain plasma or lipoproteins were assayed for the presence of endotoxin by a chromogenic modification of the Limulus test. Solutions containing plasma or lipoproteins underwent chloroform extraction prior to chromogenic Limulus testing.

For the chromogenic Limulus assay, test solutions $(0.1 \mathrm{ml})$ were added to $0.1 \mathrm{ml}$ Limulus lysate (Sigma Chemical Co.) reconstituted to 20-fold less than the manufacturer's recommended concentration with endotoxin-free $\mathrm{H}_{2} \mathrm{O}$ and then incubated in a water bath at $37^{\circ} \mathrm{C}$ for 60 min. Next, $0.4 \mathrm{ml}$ of $0.5 \mathrm{mM}$ chromogenic substrate S-2222 (Helena Laboratories, Beaumont, TX), reconstituted using endotoxin-free PBS, was added, and the mixture was incubated at $37^{\circ} \mathrm{C}$ for an additional $30 \mathrm{~min}$ before the reaction was quenched by the addition of 0.4 $\mathrm{ml} 60 \%$ glacial acetic acid. Absorption of the final mixture was measured at $405 \mathrm{~nm}$ using a spectrophotometer (Cary model 219, Varian Instrument Co., Sugar Land, TX) with distilled $\mathrm{H}_{2} \mathrm{O}$ as a zero. The assay was linear over a range of $10-100 \mathrm{pg}$ endotoxin $/ \mathrm{ml}$.

Because of the poorly defined interaction between plasma and the Limulus enzymes, the assay of endotoxin in samples containing or derived from plasma has quantitative inaccuracies $(21,25,26)$. To avoid these inaccuracies, we extracted the lipoprotein preparations with chloroform before chromogenic Limulus testing. The chloroform extraction technique (21) is an accepted method for removing the inhibitory property of plasma, and thereby allowing detection of contained endotoxin by the Limulus test. Unlike techniques which rely on a combination of heating and dilution to remove the inhibitory property of plasma, the chloroform extraction technique separates the lipid and protein constituents of plasma from contained endotoxin and allows analysis of a more concentrated sample.

Chloroform extraction of samples was performed by the method of Levin et al. (21) with a few modifications. Briefly, the plasma- or lipoprotein-containing solution was mixed in a ratio of $4: 1$ ( $\mathrm{vol} / \mathrm{vol})$ with chloroform and vortexed vigorously for $5 \mathrm{~min}$ at $25^{\circ} \mathrm{C}$. The resultant emulsion was then incubated at $37^{\circ} \mathrm{C}$ for $180 \mathrm{~min}$ in a water bath during which time it was vortexed hourly. Then the emulsion was separated by centrifugation at $2,000 \mathrm{~g}$ for $20 \mathrm{~min}$ into a top aqueous layer, a middle protein layer, and a bottom chloroform layer. The top aqueous layer was recovered and assayed for endotoxin.

As presented in detail in the results, a standard curve utilizing known quantities of endotoxin mixed with lipoprotein solutions and then extracted is used to calculate endotoxin concentrations. This procedure is necessary because even though chloroform extraction of plasma samples improves the detection of endotoxin by the Limulus test, this technique does not give linear quantification of endotoxin at low concentrations.

Lethality studies. Six-wk-old male C57BL/6J mice (15-18 g) were obtained from Bantin and Kingman, Fremont, CA. To prepare endotoxin-lipoprotein complexes, lipoproteins in endotoxin-free PBS were incubated with a final concentration of $400 \mathrm{ng} / \mathrm{ml}$ of endotoxin and $0-50 \%$ lipoprotein-free plasma. This mixture was incubated at $37^{\circ} \mathrm{C}$ for up to $6 \mathrm{~h}$ with hourly vortexing. The final volume of the endotoxin-lipoprotein complexes administered to each mouse was $0.5 \mathrm{ml}$.

Each experimental group contained at least five mice. To sensitize the mice to the toxic effects of endotoxin each mouse received an intraperitoneal injection of $18 \mathrm{mg}$ D-galactosamine hydrochloride (27) immediately before the endotoxin-lipoprotein mixture. After the injection the mice were maintained in standard mice cages with food and water ad libitum for $24 \mathrm{~h}$ at which time the number of surviving mice was determined.

Statistical analysis. Statistical significance for Figs. 1-3 was determined by chi square $\left(\chi^{2}\right)$ analysis. Data in Table $I$ are presented as the mean \pm SEM with statistical significance determined by the MannWhitney sum rank test.

\section{Results}

Effect of VLDL and chylomicrons on endotoxin-induced death. Control animals injected with endotoxin $(200 \mathrm{ng} / 0.5 \mathrm{ml})$ in 
$50 \%$ lipoprotein-free plasma had a survival rate of $27 \%$ (Fig. 1). Mice injected with endotoxin in PBS had a survival rate of only $7 \%$ (Fig. 1). When the same dose of endotoxin was incubated with increasing concentrations of VLDL or chylomicrons before injection, mice were increasingly protected from endotoxin-induced death (Fig. 1). The mice had a survival rate of $100 \%$ when the incubation mixture contained at least 10.0 $\mathrm{mg}$ of VLDL TG/ml $(P \leq 0.001)$ or $3.0 \mathrm{mg}$ of chylomicron $\mathrm{TG} / \mathrm{ml}(P \leq 0.001)$. Complete protection was also observed when adequate concentrations of LDL $(0.5 \mathrm{mg}$ of total cholesterol $[\mathrm{TC}] / \mathrm{ml}, P \leq 0.001)$ or HDL $(0.05 \mathrm{mg}$ of TC/ml, $P$ $\leq 0.001$ ) were included in the endotoxin-lipoprotein mixture (Fig. 1).

The finding that TG-rich as well as cholesterol-rich lipoproteins could protect against endotoxin-induced death led us to test whether a nonlipoprotein lipid particle, SOYACAL, could also protect under these conditions. SOYACAL is a lipid emulsion that contains neutral TGs and no cholesterol. The survival rate of mice injected with endotoxin mixtures containing SOYACAL increased with increasing amounts of SOYACAL TG (Fig. 1), reaching $100 \%$ at a concentration of $5.0 \mathrm{mg}$ SOYACAL TG/ml $(P \leq 0.001)$.

Effect of manipulating the in vitro incubation variables on endotoxin-induced death. Mouse survival increased in parallel with increasing concentrations of lipoprotein-free plasma in the endotoxin-lipoprotein mixture containing SOYACAL or LDL. As the concentration of lipoprotein-free plasma increased from 0 to $\geq 10 \%$, the survival rate increased from $7 \%$ to $100 \%$ (Fig. 2).

Mouse survival increased in parallel with the length of time the endotoxin-lipoprotein mixture was incubated in 50\% lipoprotein-free plasma before intraperitoneal injection (Fig. 3).

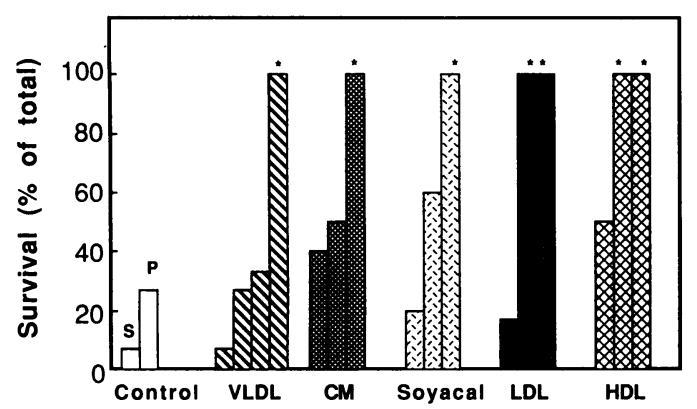

Figure 1. Increasing survival of endotoxin-treated mice after increasing concentrations of various lipoproteins or the TG-rich lipid emulsion Soyacal were incubated with $E$. coli 055:B5 endotoxin (400 $\mathrm{ng} / \mathrm{ml}$ ) and $50 \%$ lipoprotein-free plasma for $6 \mathrm{~h}$ at $37^{\circ} \mathrm{C}$ before injection. The Control columns represent the injection of endotoxin incubated in saline $(S ; n=15)$ or lipoprotein-free plasma $(P ; n=124)$. The concentrations of VLDL, chylomicrons $(C M)$, and Soyacal in the endotoxin-lipoprotein mixtures were quantified by their TG content. The following concentrations of TG-rich particles were tested; VLDL: $1.0,3.0,5.0$, and $10.0 \mathrm{mg} \mathrm{TG} / \mathrm{ml},(n=10,12,12$, and 12 , respectively); chylomicrons: $0.5,1.0$, and $3.0 \mathrm{mg} \mathrm{TG} / \mathrm{ml},(n=10,10$, and 11); Soyacal: $1.0,2.5$, and $5.0 \mathrm{mg} \mathrm{TG} / \mathrm{ml},(n=5,5$, and 11$)$. The concentrations of LDL and HDL in the endotoxin-lipoprotein mixtures were quantified by their total cholesterol content. The following concentrations of cholesterol-rich particles were tested; LDL: $0.25,0.5$, and $1.0 \mathrm{mg} \mathrm{TC} / \mathrm{ml}(n=6,12$, and 12); HDL: 0.01, 0.05 , and $0.17 \mathrm{mg} \mathrm{TC} / \mathrm{ml}(n=6,6$, and 18). Statistical significance was determined using the plasma control. *Significantly different from control, ${ }^{*} P<0.001$.

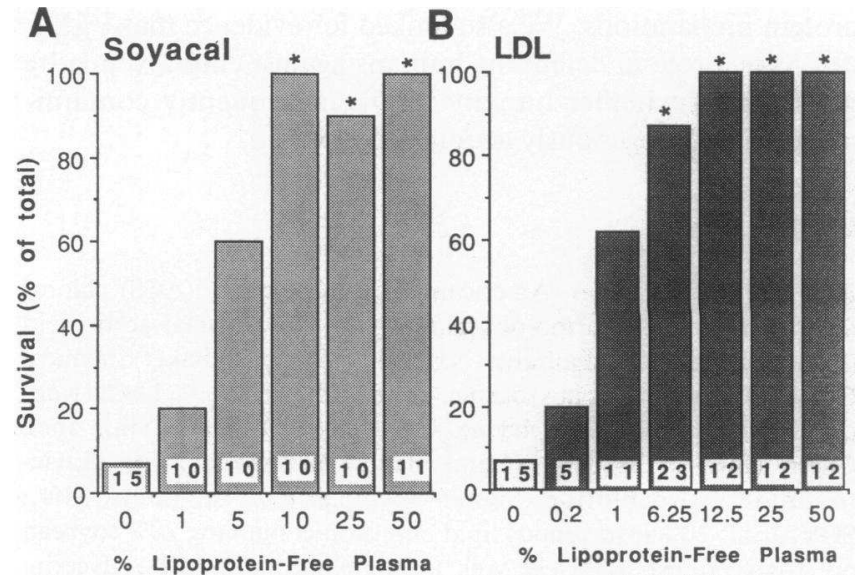

Figure 2. Effect of increasing concentrations of lipoprotein-free plasma on the survival of endotoxin-treated mice given $(A)$ the TGrich lipid emulsion Soyacal or $(B)$ LDL. Experiments were done using $5.0 \mathrm{mg}$ of Soyacal TG/ml or $1.0 \mathrm{mg}$ of LDL TC/ml incubated with $E$. coli 055 :B5 endotoxin $(400 \mathrm{ng} / \mathrm{ml})$ for $6 \mathrm{~h}$ at $37^{\circ} \mathrm{C}$ before injection. Soyacal or LDL containing no lipoprotein-free plasma served as a control. *Significantly different from control, ${ }^{*} P<0.001$. The number inside each bar represents the total number of mice in that group.

Combining the results from both SOYACAL and LDL, the survival rate of the mice was $50 \%(P=0.23)$ when the mixture was injected immediately after mixing, with no incubation time. The survival rate increased to $70 \%(P<0.02)$ after an incubation time of $1 \mathrm{~h}$, and to $100 \%$ at $3 \mathrm{~h}(P \leq 0.001)$.

Endogenous contamination of native $V L D L$. We then examined whether lipoproteins collected under conditions carefully designed to prevent exogenous endotoxin contamination contained detectable quantities of endotoxin. To determine the sensitivity of the chloroform extraction technique, we first generated standard curves comparing the detection of endotoxin added to LDL or SOYACAL solutions versus endotoxin added to saline (Fig. 4). To estimate the sensitivity of the chloroform extraction technique in our study we incubated LDL $([\mathrm{TC}]=1.0 \mathrm{mg} / \mathrm{ml})$ or SOYACAL $([\mathrm{TG}]=5.0 \mathrm{mg} / \mathrm{ml})$, as representative cholesterol-rich and TG-rich lipoprotein particles that had no endotoxin detectable by the extraction technique, with increasing concentrations of endotoxin for $3 \mathrm{~h}$ at $37^{\circ} \mathrm{C}$ before chloroform extraction. Identical concentrations

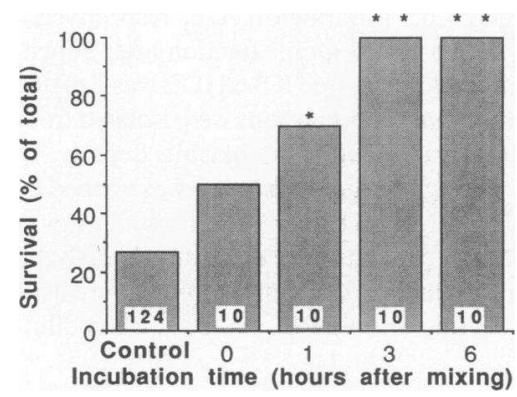

Figure 3. Effect of incubation time of the endotoxin-lipoprotein mixture on the survival of endotoxin-treated mice. The results from experiments performed using $1.0 \mathrm{mg}$ of $\mathrm{LDL}$ $\mathrm{TC} / \mathrm{ml}$ and $5.0 \mathrm{mg}$ of SOYACAL TG/ml were pooled. Lipid particles were incubated with $E$. coli 055:B5 en-

dotoxin $(400 \mathrm{ng} / \mathrm{ml})$ and $50 \%$ lipoprotein-free plasma at $37^{\circ} \mathrm{C}$. ${ }^{*, * *}$ significantly different from control; ${ }^{*} P<0.02,{ }^{* *} P<0.001$. The number inside each bar represents the total number of mice in that group. 


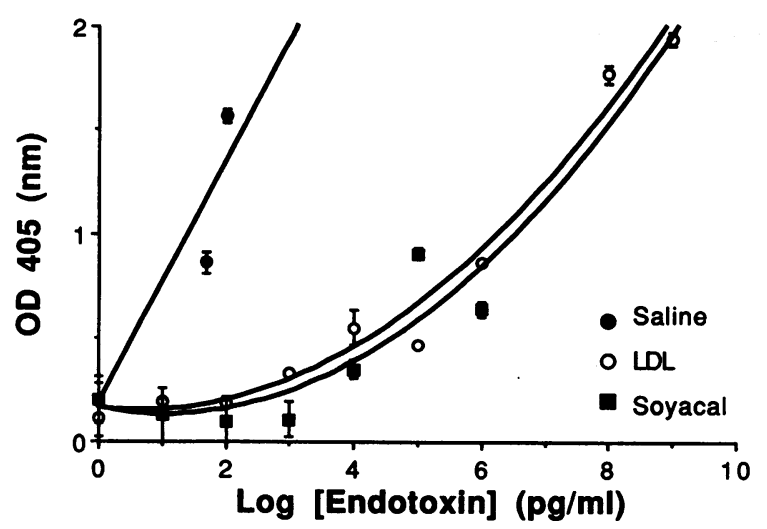

Figure 4. Ability of the chloroform extraction technique to detect endotoxin bound to LDL or SOYACAL. Increasing concentrations of E. coli 055:B5 endotoxin were incubated with $50 \%$ lipoprotein-free plasma and $1.0 \mathrm{mg}$ of LDL TC/ml or $5.0 \mathrm{mg}$ of Soyacal TG/ml for 3 h at $37^{\circ} \mathrm{C}$ before chloroform extraction and chromogenic Limulus testing. Extraction of endotoxin incubated with saline served as a control. The data are the mean \pm SD of at least three determinations, presented as a semilog plot. The SD is omitted when it is smaller than the data point. A binomial equation is generated which best describes each set of data points. LDL: $Y=0.16-0.04 X+0.03 X^{2}, r$ $=0.99$; SOYACAL: $Y=0.16-0.06 X+0.03 X^{2}, r=0.84$; Saline: $Y$ $=0.16+0.58 X, r=0.92$.

of endotoxin in sterile, apyrogenic saline were incubated and then extracted as a control. Comparison of the LDL or SOYACAL data with the saline control provided us with an estimate of how effectively the chloroform extraction technique detects endotoxin in solutions containing lipoproteins. The chloroform extraction technique was unable to reliably detect endotoxin in LDL or SOYACAL solutions when the concentration of added endotoxin was $\leq 1 \mathrm{ng} / \mathrm{mg}$ lipoprotein lipid. However, when the added endotoxin concentration was $>1 \mathrm{ng} / \mathrm{mg}$ lipoprotein lipid the chloroform extraction technique was reliable but insensitive, detecting up to 100,000 -fold less endotoxin in the LDL or SOYACAL samples as compared to the saline solution. Thus, although the chloroform extraction technique can detect endotoxin contamination of lipoproteins, it significantly underestimates the quantity of endotoxin present. Therefore, the quantity of endotoxin in the lipoprotein samples was estimated using a standard curve of extracted lipoprotein samples (see equations, Fig. 4) and a daily standard curve of endotoxin in saline.
Of the $10 \mathrm{VLDL}$ preparations, 8 were contaminated by endotoxin in both duplicate tubes (Table I). The mean concentration of endotoxin in VLDL was $5,755 \pm 3,514 \mathrm{ng} / \mathrm{mg}$ TG (mean \pm SEM). In contrast, LDL and HDL isolated sequentially by further ultracentrifugation steps from the same plasma rarely had detectable endotoxin, even though these lipoproteins underwent more extensive handling and processing during their isolation than did VLDL. Of the $10 \mathrm{LDL}$ preparations, 3 had low levels of endotoxin, but only in one of the duplicate tubes. Of the eight HDL preparations isolated in duplicate, only two preparations contained detectable endotoxin, again only in one duplicate tube. The mean detectable concentration of endotoxin in VLDL was significantly higher than that found in LDL or HDL (both $P<0.001$ ).

\section{Discussion}

Early studies examining the effect of serum on endotoxin were directed at understanding the mechanism by which serum reduced the toxicity of endotoxin $(28,29)$. From these studies Skarnes et al. (30) suggested that endotoxin might interact with $\beta$ - and $\alpha_{1}$-lipoproteins with a resultant modification of endotoxin's physical and immunochemical properties. Subsequently, Ulevitch and Johnston (13) demonstrated that the incubation of endotoxin with serum, both in vitro and in vivo, reduced its buoyant density and subsequent toxicity. It has been proposed that after incubation with serum, endotoxin is first disaggregated and then binds to HDL to form a stable lipoprotein-endotoxin complex (14). This process is time-, temperature-, and plasma-dependent $(16,29,31)$. Whereas these studies of the interaction between lipoproteins and endotoxin have primarily focused on HDL, a recent study has suggested that VLDL, $\beta$-VLDL, LDL, as well as HDL can bind endotoxin in direct proportion to their plasma cholesterol content (18). Although the focus of this study was the interaction of endotoxin with LDL, since this lipoprotein contains the predominant amount of plasma cholesterol in most animal species, the data also show that VLDL from New Zealand White, cholesterol-fed New Zealand White, and Watanabe heritable hyperlipidemic rabbits bound $9 \%, 35 \%$, and $27 \%$ of radiolabeled endotoxin in vitro, respectively. A higher percentage was found bound to the $d \leq 1.006 \mathrm{~g} / \mathrm{cm}^{3}$ fraction of plasma after injection of endotoxin in vivo (18).

Interestingly, most studies that have previously examined the ability of VLDL to interact with endotoxin concluded that these TG-rich lipoproteins had minimal endotoxin binding

Table I. Endotoxin Contamination of Ultracentrifugally Isolated Lipoproteins

\begin{tabular}{|c|c|c|c|c|c|c|c|c|c|c|c|c|}
\hline \multirow[b]{2}{*}{ Lipoprotein } & \multicolumn{12}{|c|}{ Endotoxin (ng/mg lipoprotein lipid) } \\
\hline & $(A)$ & (B) & (C) & (D) & $(E)$ & $(F)$ & $(G)$ & $(H)$ & $(I)$ & $(J)$ & $\bar{\chi}$ & SEM \\
\hline VLDL \#1 & 42,835 & 162 & $<1$ & $<1$ & 40 & 8,314 & 114 & 113 & 125 & 496 & \multirow{2}{*}{5,755} & \multirow{2}{*}{3,514} \\
\hline VLDL \#2 & 58,700 & 584 & $<1$ & $<1$ & 2,000 & 370 & 794 & 132 & 284 & 36 & & \\
\hline LDL \# 1 & $<1$ & $<1$ & $<1$ & 1 & ND & $<1$ & $<1$ & $<1$ & $<1$ & $<1$ & \multirow{2}{*}{3} & \multirow{2}{*}{3} \\
\hline LDL \#2 & $<1$ & $<1$ & $<1$ & $<1$ & 49 & 2 & $<1$ & $<1$ & $<1$ & $<1$ & & \\
\hline HDL \# 1 & ND & $<1$ & 5,112 & ND & $<1$ & $<1$ & $<1$ & $<1$ & $<1$ & $<1$ & \multirow{2}{*}{320} & \multirow{2}{*}{319} \\
\hline HDL \#2 & ND & $<1$ & $<1$ & ND & 2 & $<1$ & $<1$ & $<1$ & $<1$ & $<1$ & & \\
\hline
\end{tabular}

Lipoprotein samples were isolated in duplicate from the plasma of ten healthy volunteers (A-J) by an ultracentrifugation procedure modified to avoid contamination of samples by exogenous endotoxin. Samples were assayed for endotoxin content by chloroform extraction followed by chromogenic Limulus testing. VLDL vs. LDL or HDL, $P<0.001$; LDL vs. HDL, $P>0.87$. ND, no data; samples lost during isolation. 
capacity as compared to LDL or HDL. In contrast, our results demonstrate that incubation of the triglyceride-rich VLDL or chylomicrons with endotoxin can effectively protect mice against endotoxin-induced death. We have also shown that the TG-rich lipid emulsion SOYACAL can protect mice from endotoxin-induced death. Since all of these particles are large and rich in triglyceride, and contain little or in the case of SOYACAL contain no cholesterol, these results show that cholesterol is not essential or necessary for the interaction between endotoxin and lipoproteins to take place. Furthermore, the protective ability of all lipoproteins tested, including LDL and HDL, was directly dependent on the concentration of lipoprotein lipid present in the endotoxin-lipoprotein mixtures. Specifcally, injection of $3.0 \mathrm{mg}$ of chylomicron $\mathrm{TG} / \mathrm{ml}, 10.0 \mathrm{mg}$ VLDL TG/ml, $0.5 \mathrm{mg} \mathrm{LDL} \mathrm{TC/ml,} 0.05 \mathrm{mg} \mathrm{HDL} \mathrm{TC} / \mathrm{ml}$, or $5.0 \mathrm{mg}$ SOYACAL $\mathrm{TG} / \mathrm{ml}$ incubated with $50 \%$ lipoproteinfree plasma and a lethal dose of $E$. coli endotoxin resulted in a mouse survival rate of $100 \%$. Since the lethal effect of endotoxin can be prevented by lipid particles enriched in either triglyceride or cholesterol, as well as phospholipid, we presume that a lipid-glycolipid interaction must be at least partially responsible for this phenomenon. Given the data that phospholipids can not only interact directly with endotoxin (32), but potentially play a critical role in the interaction of endotoxins with cell membranes (33) and liposomes (34), the binding of endotoxin to lipoproteins may be dependent on a phospholipid-glycolipid interaction $(35,36)$.

Manipulation of the in vitro incubation variables showed that neutralization of endotoxin by lipoproteins or SOYACAL was directly dependent on the quantity of lipoprotein-free plasma present in the endotoxin-lipoprotein mixtures and the length of time the mixtures were incubated together before their injection. As in previous studies, lipoprotein-free plasma was required for all lipoproteins to prevent endotoxin-induced death, and a concentration of as low as $10 \%$ proved effective. The shortest incubation time that resulted in $100 \%$ survival was $3 \mathrm{~h}$. However, there was an increased survival rate after $1 \mathrm{~h}$ and a trend towards an increase in the survival rate when there was no incubation time as compared to the control, but this difference failed to reach statistical significance.

Our data also demonstrate that VLDL is frequently contaminated by endotoxin. This finding raises the possibility that previous studies which reported no significant interaction between VLDL and endotoxin may have used VLDL that was contaminated with endotoxin $(14,18)$. These studies did not detail extensive methods to prevent exogenous endotoxin contamination. Also, their lipoprotein preparations were not assayed for the presence of endotoxin before use. In contrast, in this study we strictly adhered to apyrogenic technique, which required the steam sterilization and dry heating of all materials used, including stainless steel tubes with custom-crafted silicone O-rings for the isolation of lipoproteins by sequential ultracentrifugation. Because routine steps in the sequential isolation of lipoproteins, including the recovery of supernatants, adjustment of densities, saline dialysis, and storage, represent opportunities for significant exogenous endotoxin contamination, the isolation of endotoxin-free lipoproteins, especially VLDL, required careful attention to detail and technique. Therefore plasma samples were routinely processed in duplicate to assist in identifying potential breaks in apyrogenic technique. Despite these precautions we still found that $80 \%$ of the VLDL isolated from 10 healthy volunteers contained detectable levels of endotoxin, averaging $5,755 \mathrm{ng} / \mathrm{mg}$ lipoprotein lipid. In contrast, LDL and HDL isolated sequentially from the same plasma samples were almost always free of endotoxin. Theoretically, the detected endotoxin could have been of exogenous origin in spite of our attempts to limit exogenous contamination. But, as illustrated in Table I, when VLDL contained endotoxin, it was uniformly detected in both duplicate samples which is consistent with the endogenous sequestration of endotoxin in vivo. This is in contrast to the pattern of contamination detected in the LDL and HDL samples, where four samples contained endotoxin detectable in only one of the two duplicate tubes. A fifth sample also contained endotoxin but was assayed in a single tube. This pattern of LDL and HDL contamination is compatible with the detection of exogenous endotoxin introduced during the isolation procedure. However, the low levels of contamination in four of the five tubes were so near the assay's level of sensitivity as to allow the possibility that the uncontaminated duplicate tubes actually were contaminated but at a level that could not be detected.

The data reveal that there is a wide variation in the concentrations of detectable endotoxin in the VLDL samples. The variation between samples may be a reflection of the interaction between VLDL and endotoxin in vivo. The contamination of VLDL with endotoxin is presumably the result of incidental endotoxemias which are spontaneous events that could vary in their magnitude.

Because of the frequency with which we found VLDL contamination, it is difficult to accurately estimate how much of this lipoprotein is required to detoxify equivalent amounts of endotoxin. Although numerous VLDL samples were obtained, only those which contained low levels of detectable endotoxin by chloroform extraction ( $\leq 100 \mathrm{ng}$ of endotoxin/ mg of VLDL TG) were used to determine VLDL's protective ability. Each mouse received $200 \mathrm{ng}$ of endotoxin. Since the VLDL preparations used in the survival data reported here did contain some detectable endotoxin, we presume that the concentration of VLDL TG required for $100 \%$ mouse survival is artifactually increased.

Our ability to quantitate the contamination of lipoprotein preparations by endotoxin is insensitive. Despite application of the chloroform extraction technique we show that extraction of either cholesterol-rich (LDL) or TG-rich (SOYACAL) particles does not reliably detect endotoxin concentrations $<1$ $\mathrm{ng} / \mathrm{mg}$ lipoprotein lipid. Although we cannot conclusively demonstrate that isolated samples of LDL and HDL do not contain any endotoxin it would appear that these lipoproteins contain much less endotoxin than does VLDL. It is unlikely that the difference in detectable endotoxin content between the TG-rich VLDL and the cholesterol-rich LDL and HDL reflects a difference in the chloroform extraction properties of these two classes of lipoprotein because we extracted samples containing LDL and samples containing SOYACAL, and observed no difference in the assay's efficiency in detecting endotoxin contamination of these two compositionally distinct particles. Difficulty isolating VLDL samples free of endotoxin prevented us from using this particular lipoprotein to determine the sensitivity of the chloroform extraction technique for detecting endotoxin contamination of lipoprotein samples.

The E. coli (055:B5) endotoxin used in this study was derived from a commonly employed, readily available strain of bacteria (37-39). Since the endotoxin was isolated via the phenol extraction technique of Westphal et al. (20), it may have contained some lipid A-associated protein (40), a poten- 
tially biologically active substance. Although we did not assay for the presence of lipid A-associated protein in our endotoxin preparation, it is possible that endotoxin preparations free of this protein could prove even less toxic than we have demonstrated here. The ability of TG-rich lipid particles to decrease the toxicity of other serotypes and strains of endotoxin warrants further investigation.

The observations that human VLDL and chylomicrons can interact in vitro with endotoxin to prevent its lethal effect in mice, and that human VLDL is frequently contaminated with endotoxin, whereas LDL and HDL are not, may have many potential implications. VLDL, in addition to their role in triglyceride transport, may also function as part of a defensive mechanism to combat the serious pathophysiologic sequellae of endotoxemia. In addition to our results, this theory is supported by the finding that when animals or humans are challenged with infectious agents or endotoxin there are significant changes in the distribution of circulating lipoproteins (4-10, 41, 42). A consistent early finding is an increase in the concentration of circulating VLDL (8-10). This increase in VLDL is now known to be mediated by cytokines, in particular, tumor necrosis factor (43-45). The increase in VLDL could be an attempt by the body to bind and neutralize the toxic effects of any circulating endotoxin. If VLDL functions as part of a defensive mechanism, then the neutralization of endotoxin by circulating TG-rich lipoproteins could help explain why transient endotoxemias, despite their frequency, remain asymptomatic. Daily activities in healthy people, such as tooth brushing and defecating, often introduce endotoxin into the circulation.

In summary, this study shows that VLDL, chylomicrons, and SOYACAL can protect mice against endotoxin-induced death. Since there is little or no cholesterol in these lipid particles, the interaction between endotoxin and lipoproteins does not appear to be determined solely by the lipoproteins' cholesterol content. We, as have others, further show that the interaction between endotoxin and lipoproteins is dependent on a number of in vitro incubation variables. Lastly, the fact that human VLDL is frequently contaminated with endotoxin of probable endogenous origin raises the possibility that increased triglyceride-rich lipoproteins play a role in the host's defense against endotoxemia and infection.

\section{Acknowledgments}

The technical advice of Robert I. Roth and Jack Levin, and the able technical assistance of Judy Tweedie, Arthur H. Moser, and Saleh Adi are greatly appreciated.

This work was supported in part by grants HL41470, HL07737, and DK 40990 from the National Institutes of Health, and grants from the Achievement Rewards for College Scientists (ARCS) Foundation, the Veterans Administration, the Pacific Vascular Research Foundation, and the University of California University-Wide Task Force on AIDS. Dr. Grunfeld is a Clinical Investigator of the Veterans Administration.

\section{References}

1. Wolff, S. M. 1973. Biological effects of bacterial endotoxins in man. J. Infect. Dis. 128:S259-S264.

2. Gilbert, R. P. 1960. Mechanisms of the hemodynamic effect of endotoxin. Physiol. Rev. 40:245-279.

3. Morrison, D. C., and R. J. Ulevitch. 1978. The effects of bacterial endotoxins on host mediation systems. Am. J. Pathol. 93:525-617.
4. Gallin, J. I., D. Kaye, and W. M. O'Leary. 1969. Serum lipids in infection. N. Engl. J. Med. 281:1081-1086.

5. Fiser, R. H., J. C. Denniston, and W. R. Beisel. 1972. Infection with Diplococcus pneumoniae and Salmonella typhimurium in monkeys: changes in plasma lipids and lipoproteins. J. Infect. Dis. 125:5460.

6. Alvarez, C., and A. Ramos. 1986. Lipids, lipoproteins, and apoproteins in serum during infection. Clin. Chem. 32:142-145.

7. Cabana, V. G., J. N. Siegel, and S. M. Sabesin. 1989. Effects of the acute phase response on the concentration and density distribution of plasma lipids and apolipoproteins. J. Lipid Res. 30:39-49.

8. Sammalkorpi, K., V. Valtonen, Y. Kerttula, E. Nikkila, and M. Taskinen. 1988. Changes in serum lipoprotein pattern induced by acute infections. Metab. Clin. Exp. 37:859-865.

9. Sakaguchi, S. 1982. Metabolic disorders of serum lipoproteins in endotoxin-poisoned mice: the role of high density lipoprotein (HDL) and triglyceride-rich lipoproteins. Microbiol. Immunol. 26:1017-1034.

10. Lanza-Jacoby, S., S. C. Lansey, M. P. Cleary, and F. E. Rosato. 1982. Alterations in lipogenic enzymes and lipoprotein lipase activity during gram-negative sepsis in the rat. Arch. Surg. 117:144-147.

11. Wolfe, R. R., J. H. F. Shaw, and M. J. Durkot. 1985. Effect of sepsis on VLDL kinetics: responses in basal state and during glucose infusion. Am. J. Physiol. 248:E732-E740.

12. Masoro, E. J. 1977. Fat metabolism in normal and abnormal states. Am. J. Clin. Nutr. 30:1311-1320.

13. Ulevitch, R. J., and A. R. Johnston. 1978. The modification of the biophysical and endotoxic properties of bacterial lipopolysaccharide by serum. J. Clin. Invest. 62:1313-1324.

14. Ulevitch, R. J., A. R. Johnston, and D. B. Weinstein. 1979. New function for high density lipoproteins: their participation in intravascular reactions of bacterial lipopolysaccharides. J. Clin. Invest. 64:1516-1524.

15. Ulevitch, R. J., A. R. Johnston, and D. B. Weinstein. 1981. New function for high density lipoproteins: isolation and characterization of a bacterial lipopolysaccharide-high density lipoprotein complex formed in rabbit plasma. J. Clin. Invest. 67:827-837.

16. Ulevitch, R. J. 1985. Interactions of bacterial lipopolysaccharides and plasma high density lipoproteins. In Cellular Biology of Endotoxin. Handb. Endotoxin. 3:372-388.

17. Mathison, J. C., and R. J. Ulevitch. 1981. In vivo interaction of bacterial lipopolysaccharide (LPS) with rabbit platelets: modulation by C3 and high density lipoproteins. J. Immunol. 126:1575-1580.

18. Van Lenten, B. J., A. M. Fogelman, M. E. Haberland, and P. A. Edwards. 1986. The role of lipoproteins and receptor-mediated endocytosis in the transport of bacterial lipopolysaccharide. Proc. Natl. Acad. Sci. USA. 83:2704-2708.

19. Navab, M., G. P. Hough, B. J. Van Lenten, J. A. Berliner, and A. M. Fogelman. 1988. Low density lipoproteins transfer bacterial lipopolysaccharides across endothelial monolayers in a biologically active form. J. Clin. Invest. 81:601-605.

20. Westphal, V. O., O. Luderitz, and F. Bister. 1952. Über die extraktion von bakterien mit phenol/wasser. Z. Naturforschg. $7 B: 148-155$.

21. Levin, J., P. A. Tomasulo, and R. S. Oser. 1970. Detection of endotoxin in human blood and demonstration of an inhibitor. J. Lab. Clin. Med. 75:903-911.

22. Jacob, A. I., P. K. Goldberg, N. Bloom, G. A. Degenshein, and P. J. Kozinn. 1977. Endotoxin and bacteria in portal blood. Gastroenterology. 72:1268-1279.

23. Gould, M. J., and T. J. Novitsky. 1985. Depyrogenation by hydrogen pyroxide. In Technical Report No. 7, Depyrogenation. Parenteral Drug Association, Inc., Philadelphia. 84-92.

24. Havel, R. J., H. A. Eder, and J. H. Bragdon. 1955. The distribution and chemical composition of ultracentrifugally separated lipoproteins in human serum. J. Clin. Invest. 34:1345-1353.

25. Harris, R. I., P. C. W. Stone, and J. Stuart. 1983. An improved chromogenic substrate endotoxin assay for clinical use. J. Clin. Pathol. 36:1145-1149.

26. Obayashi, T. 1984. Addition of perchloric acid to blood sam- 
ples for colorimetric Limulus test using chromogenic substrate: comparison with conventional procedures and clinical applications. J. Lab. Clin. Med. 104:321-330.

27. Lehmann, V., M. A. Freudenberg, and C. Galanos. 1987. Lethal toxicity of lipopolysaccharide and tumor necrosis factor in normal and D-galactosamine-treated mice. J. Exp. Med. 165:657-663.

28. Rosen, F. S., R. C. Skarnes, M. Landy, and M. J. Shear. 1958 Inactivation of endotoxin by a humoral component. III. Role of divalent cation and a dialyzable component. J. Exp. Med. 108:701-711.

29. Skarnes, R. C., F. S. Rosen, M. J. Shear, and M. Landy. 1958. Inactivation of endotoxin by a humoral component. II. Interaction of endotoxin with serum and plasma. J. Exp. Med. 108:685-700.

30. Skarnes, R. C. 1966. The inactivation of endotoxin after interaction with certain proteins of normal serum. Ann. NY Acad. Sci. 133:644-662.

31. Warren, H. S., C. V. Knights, and G. R. Siber. 1986. Neutralization and lipoprotein binding of lipopolysaccharides in tolerant rabbit serum. J. Infect. Dis. 154:784-791.

32. Takeuchi, Y., and H. Nikaido. 1984. Physical interaction between lipid A and phospholipids: a study with spin-labeled phospholipids. Rev. Infect. Dis. 6:488-492.

33. Shands, J. W. 1973. Affinity of endotoxin for membranes. $J$. Infect. Dis. 128 (Suppl.):197-201.

34. Alving, C. R., and E. C. Richardson. 1984. Mitogenic activities of Lipid A and liposome-associated Lipid A: effects of epitope density. Rev. Infect. Dis. 6:493-496.

35. Benedetto, D. A., J. W. Shands, and D. O. Shah. 1973. The interaction of bacterial lipopolysaccharide with phospholipid bilayers and monolayers. Biochim. Biophys. Acta. 298:145-157.

36. Fried, V. A., and L. I. Rothfield. 1978. Interactions between lipopolysaccharide and phosphatidylethanolamine in molecular monolayers. Biochim. Biophys. Acta. 514:69-82.
37. Pearson, F. C., M. E. Weary, H. E. Sargent, T. J. Novitsky, H. Lin, G. Lindsay, R. N. Berzofsky, A. L. Lane, J. D. Wilson, J. F. Cooper, et al. 1985. Comparisons of several control standard endotoxins to the national reference standard endotoxin-an HIMA collaborative study. Appl. Environ. Microbiol. 50:91-93.

38. Tobias, P. S., K. Soldau, and R. J. Ulevich. 1989. Identification of a lipid A binding site in the acute phase reactant lipopolysaccharide binding protein. J. Biol. Chem. 264:10867-10871.

39. Amaral, J. F., J. D. Shearer, B. Mastrofrancesco, D. S. Gann, and M. D. Caldwell. 1989. The effect of endotoxin on glucose metabolism in skeletal muscle requires the presence of plasma. Arch. Surg. 124:727-732.

40. Ryan, J. L., L. M. Glode, and D. L. Rosenstreich. 1979. Lack of responsiveness of $\mathrm{C} 3 \mathrm{H} / \mathrm{HeJ}$ macrophages to lipopolysaccharide: the cellular basis of LPS-stimulated metabolism. J. Immunol. 122:932935 .

41. Lees, R. S., R. H. Fiser, W. R. Beisel, and P. J. Bartelloni. 1972. Effects of an experimental viral infection on plasma lipid and lipoprotein metabolism. Metab. Clin. Exp. 21:825-833.

42. Rouzer, C. A., and A. Cerami. 1980. Hypertriglyceridemia associated with Trypanosoma brucei brucei infection in rabbits: role of defective triglyceride removal. Mol. Biomed. Parasitol. 2:31-38.

43. Feingold, K. R., and C. Grunfeld. 1987. Tumor necrosis factor-alpha stimulates hepatic lipogenesis in the rat in vivo. J. Clin. Invest. 80:184-190.

44. Feingold, K. R., M. K. Serio, S. Adi, A. H. Moser, and C. Grunfeld. 1989. Tumor necrosis factor stimulates hepatic lipid synthesis and secretion. Endocrinology. 124:2336-2342.

45. Feingold, K. R., M. Soued, M. K. Serio, A. H. Moser, C. A. Dinarello, and C. Grunfeld. 1989. Multiple cytokines stimulate hepatic lipid synthesis in vivo. Endocrinology. 125:267-274. 